\title{
Rosemary Hawker
}

The Idiom in Photography As the

Truth in Painting

While contemporary German painter Gerhard Richter is known for the diversity of his oeuvre, his so-called photo-paintings evidence a persistent return to the relationship of two traditionally opposed media. Often startling in their visual effects, these images rely on a highly rhetorical attempt to transcribe what I will label "photographic idiom" into the medium of painting. In some of Richter's works, this photographic reference appears as a high realism, one that we take for granted in the veracious medium of photography, yet cannot help but be impressed to find in painting. Richter's paintings, however, have most to say about photography in their oblique reference to the medium. Richter refers not to the visual plenitude and truth that we usually associate with photography, but rather to its moments of representational inadequacy, to photographic blur and lack of focus that results in deliberately obscured imagery. In these works - of which Lesende (1999) (Figure I) is a good example-the space between photography and painting is at once closed and reopened.

In emphasizing what is idiomatic to photography, I am drawing on the discussion of idiom that

The South Atlantic Quarterly 101:3, Summer 2002. Copyright (C) 2002 by Duke University Press. 


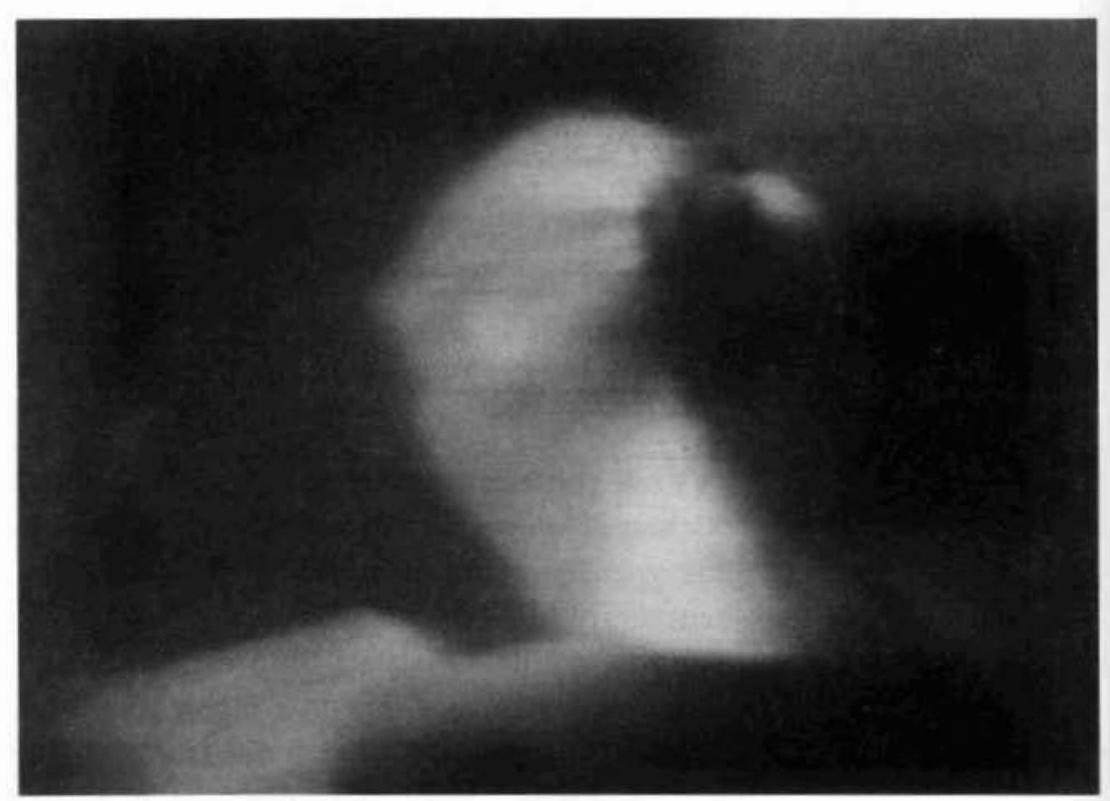

Figure I. Gerhard Richter, Lesende, 1999, no. 799-1. Courtesy Gerhard Richter.

prefaces Jacques Derrida's The Truth in Painting. ${ }^{1}$ Here, in a series of movements between idiom, painting, and truth, Derrida establishes the special status of idiom in mapping out the specificity of media. Beginning with the statement, "I am interested in the idiom in painting," Derrida poses a range of translations of this statement, all of which recast what the idiom may refer to, but none of which describe what it is. This in itself tells us something of Derrida's very specific claims for idiom.

Idiom and truth are for Derrida found to coalesce in a letter written by Cézanne, which includes the statement, "I owe you the truth in painting and I will tell it to you." ${ }^{2}$ Derrida seizes on Cézanne's promise as both a highly idiomatic statement and a powerful model of idiom. This short sentence is able to refer simultaneously, and in a manner that escapes adequate translation, to three relations of truth and painting: first, to Cézanne's knowledge of the truth of the medium; second, to the truth of the world as rendered in painting; and, third, to the truth about painting as told through language. In turning to Cézanne's statement, the idiom in painting, with which Derrida began, has now become the truth in painting. Here truth is both the problem 
of representation more broadly and specifically the problem of representing the medium of painting, or rather representing the medium of painting in writing. Derrida's final configuration of these paired terms, "I am interested in the idiom of truth in painting," completes the equation, joining idiom, truth, and painting, but only insofar as it makes clear the folly of attempting to fasten on the idiomatic, much less to reproduce it. Derrida writes:

One is always tempted by this faith in idiom: it supposedly says only one thing, properly speaking, and says it only in linking form and meaning too strictly to lend itself to translation. But if the idiom were this, were it what it is thought it must be, it would not be that, but it would lose all strength and would not make a language. ${ }^{3}$

Here Derrida identifies the paradox of idiom. We know what idiom is meant to be, we understand its functioning in language in the broadest sense. Yet when we try to extract an instance of the idiomatic for contemplation we can be sure that what we have in our sights is the appearance of a form far too nuanced to be isolated. When we use idiomatic language, we do so unselfconsciously; to become conscious of our use of idiom is to have the essential feature of that idiomatic usage slip away from us.

Richter's photo-paintings open and turn upon these same issues: "I'm not trying to imitate a photograph; I'm trying to make one. And if I disregard the assumption that a photograph is a piece of paper exposed to light, then I am practicing photography by other means." ${ }^{4}$ Richter's distinction between imitation and making is, of course, an important one. To imitate photography would simply be to reproduce its surface appearance, but to make a photograph is to claim its idiom as your own. Yet Richter's photography "by other means" is - in material other than paper exposed to lightanother medium, another language.

In Derrida's terms, an attempt to translate an idiom into another language always and necessarily results in a remainder - an idiomatic excess that cannot be accounted for in the second language. For what is idiomatic is always outside of translation. And so it is with Richter's photo-paintings. Despite telling us so much about photography's visual strategies, and in transferring these to painting, what is unique, singular, proper, and inimitable - that is, what is idiomatic to photography-remains outside of painting. In this way, this knowledge of photography is not something subsumed by painting. Painting has not taken over what photography can do. How then are 
we to understand Richter's attempts to make photographs as other than an empty rhetorical gesture?

Given what Derrida says about idiom, we might say that while Richter may promise to paint a photograph-as opposed to painting photographically - he can only do so by enacting a strategy of quotation. Samuel Weber would call this gesture a citation of photography as opposed to a direct transcription or translation of its idiom into another medium..$^{5}$ It is this very quality of citability that marks out the difference between media-in this case, between the media of photography and painting. For citation necessarily interrupts a text's context, bringing to it as it does, something from another context and this citation as interruption suspends the text's claim to totality.

In citing a photographic idiom, Richter therefore interrupts what is proper to painting, its context, and in so doing admits another mode of representation ceding any claim that painting, and by implication photography, may have had to adequately represent any claim to totality. This is certainly one of Richter's aims. Citation is used when paraphrase, précis, translation, or visual proximity will simply not do the job. In citing other languages, and thus other means of representation, we acknowledge the very particular, idiosyncratic perspective these citations can bring to our text. Therefore, the idiom of the language that is cited is not just maintained, but actively reinforced through citation. We see this in the process by which Richter's photographic citations help us know more about what is idiomatic to the medium of photography precisely by citing it rather than because of an inability to reproduce such an idiom.

On the surface, Richter's gesture is toward closing the space between photography and painting. It is not an empty rhetorical gesture, nor simply an inevitably failed translation. For the remainder that he reveals, to use Derrida's term, is what is idiomatic to the medium of photography and is paired with an equal and opposite idiomatic impulse from painting. This impulse results in the realization that the failure to translate photographic idiom into painting also rests on what is idiomatic to the medium of painting. We should recall that for Derrida the idiom becomes the truth of a medium. We can see photography through its citation in painting in a way that we cannot see it as photography. Equally, photographic idiom throws painting's practices into sharp relief. Richter's photo-paintings can then be said to enact a dialogue between these media that allows the idiom in photography to reveal the truth in painting. 


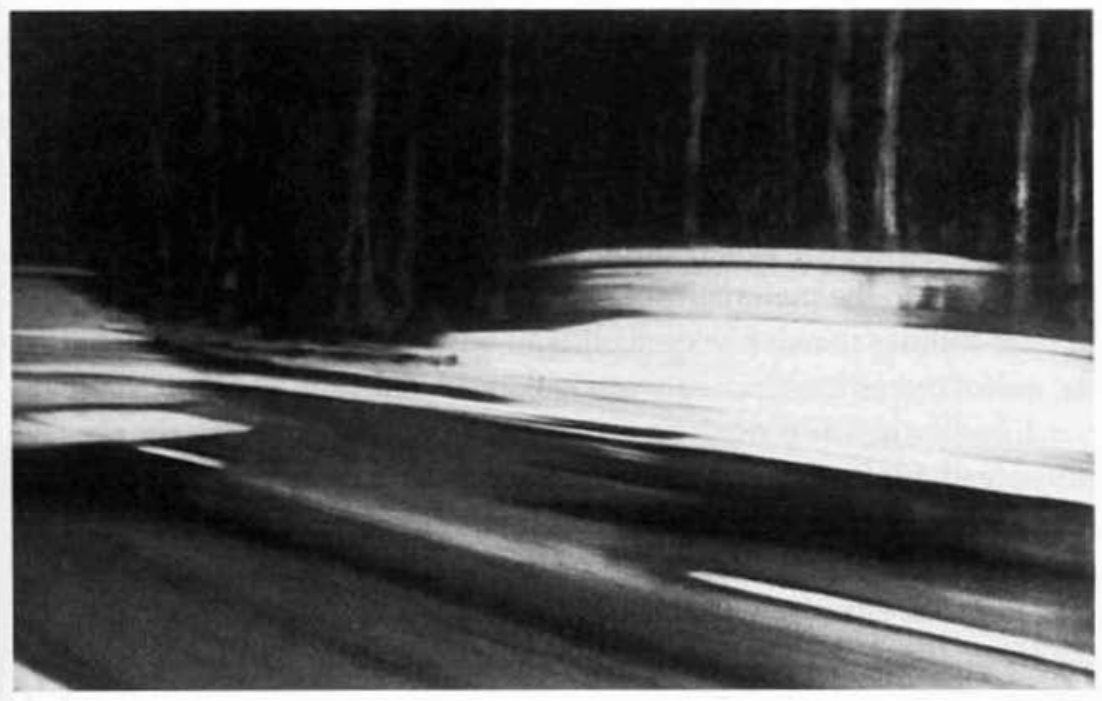

Figure 2. Gerhard Richter, Two Fiats, 1964, no. 67. Courtesy Gerhard Richter.

Two Fiats (1964), one of Richter's early photo-paintings, is a striking example of his citation of the photographic idiom in the form of a blur (Figure 2). The blur has a special place in the way we think about photography's ability to represent in ostensibly different ways than other media. In the early history of the medium the blur-ironically a sign of the shortcoming of the technology - was quickly feted as a unique photographic trait, something able to potently signify movement, speed, and the excitement of the modern age. Here Richter's concern lies with what photography and painting are able to tell us about representational uptake of visual phenomena. This image is about the capacities and limitations of the medium it is rendered in, painting, and also the medium to which it overtly refers, photography. It is so much about the limits of representation, in either media, that without the title it would be difficult to ascertain what is shown here. That these are "Fiats" and not merely "cars" provides a kind of fantasy of specificity by which an aficionado might recognize the blur made by Fiats as opposed to other marques.

In Two Fiats, a lack of visual clarity comes to equate with perceptual accuracy. In making the corporeality of our looking obvious through the physicality of the speed blur, we are reconnected to the physical fact of our looking. This is in strong contrast to certain representational strategies 
employed by photography that would have us believe that visual perception is somehow beyond the fallibility of the body. Richter slows the cars down by painting them, rendering them in a medium that insists on the contemplation of the barest visual registration of form within what is, or was, a photograph. That Richter has chosen to further confound the temporality of our experience through painting this instance of optical confusion helps us to attend to the materiality of both painting and photography as well as to their abilities to redefine each other in ways that are able to comment on the lack of correspondence between looking, perception, and representation more generally. The process as played out in this image seems the clearest possible example of the transformation of the most glancing photographic look into the painterly gaze, a clear index of the different temporality that shapes the media of photography and painting.

Richter has effectively established the blur as a sign of the untranslatable, the idiomatic. His painting of this photographic trope demonstrates that what painting is able to take from photography is appearance only, the technical means and indexical origins of the blur are specific to photography and therefore untranslatable and idiomatic. Even more than this, this blur is also distinct from natural, unmediated vision. The camera registers a blur where the eye does not-that is, the blur is idiomatic to photography, not vision. In fact, it would not seem possible to have an idiom of sight, that is, if we accept that the senses are outside of language, literally and analogously. When an object passes before our eyes too quickly to register its form, our vision fails us. And of course when we say, "It was just a blur," we engage the most familiar type of idiom, a figure of speech.

More common to Richter's œuvre than the speed blur of Two Fiats is his use of photographic "out-of-focus-ness" associated with either a mistaken reading of depth of field or the accidental movement or tremble of the operator. We can see this effect in two portraits of the artist's daughter painted eleven years apart: Betty (1977) and Betty (1988). The images originate in photographs we can assume were taken by the artist. The technique is one Richter commonly employs to produce a photographic effect, that is, to paint the image photo-realistically and then to drag a brush over the still wet paint, to "unfocus" it. There are two linked aspects of this work that articulate mediality. The first is the fact that a photographic effect is arrived at through reference to a photographic limit or mistake, which is interesting in itself. The second aspect, that the success of such a labor-intensive, 
manual technique in producing a photographic effect is itself at odds with our perceptions of photography as mechanistic and unmediated.

Why does Richter knock his work out of focus in this way? A monochrome Betty looks back from the picture plane. Her features, a collection of unanchored smudges, dislocate our immediate responses to portraiture in terms of providing a likeness. Although centuries of representational convention-first, in painting and then in photography-have led us to this habit, Richter seems to warn against looking for likeness and identity in clarity of detail or resolution. In an unlikely but pithy analogy, he writes, "You do not see less by looking at a field out of focus through a magnifying glass." Equally, one does not see more, for the camera, or the look of the camera, does not expand or deepen our perception of the world.? This is as true of all forms of representation as it is of photography, and Richter's aim is not to reveal the sham of photo-objectivity.

In this context, he does not want to show how different photography is to other media but instead how like them it is and to suggest that all representational practices are similarly inadequate. "All these failures! It is a wonder to me that the pictures ever do show the occasional flash of distinction, because basically they are all lamentable displays of incapacity and failure (failure in an attempt to overcome this incapacity)." ${ }^{8}$ And when in an interview Benjamin Buchloh asks whether it is not a contradiction that he continues to work with the same means when a change of means might achieve his aims, Richter replies, "That's not a contradiction, it's a perfectly normal state of affairs. The normal mess if you like. And that couldn't be changed by choosing different means and methods." Is this, Buchloh questions, because all means are of equal value? "No, but all [are] similarly inadequate. The question is, what are my means, and what can I achieve with them?"

The second, much-reproduced Betty (1988) is painted from a color photograph. This time the traditional fidelity of photographic representation is maintained, but there is also the infidelity of the standard depth of field limitations of photography. Not all areas of the image are in sharp focus, but even so this remains a detailed work. The quality of color and tone are photolike: saturated, bright, glossy, pure. Despite this wealth of visual information, this image is also about fractured appearances. We only see the back of Betty's head and the side of her face, and so again we are denied the visual information we expect from the genre of portraiture. This results from the generic mistake of the snapshot, the photograph taken a moment too late. 
Like the first Betty, the strength of the work lies not in what is shown, but in what is withheld. Betty shimmers, her hair is soft metal, the pattern on her jacket swims out to meet our eyes. Yet we are not satisfied in our looking, we would all have Betty turn to face us so we might see and therefore know her better. That Richter is a highly reflexive painter is underlined for us in that his daughter's attention has been taken by one of his own monochromes. In this way, her looking marks out something of the scope and diversity of Richter's oeuvre and an even broader engagement with idiomatic issues across artistic styles and art history.

Many of Richter's works make direct reference to genres and styles in art history, such as his still-life paintings, Skull (1983) or Candle (1982), with their overt references to the formula vanitas. Some involve even more specific art historical references, for example, Ema (ig66), literally a nude descending a staircase. Yet what remains common in all these cases is that Richter consistently engages, and reengages with conceptual and technical difficulties that have besieged the medium of painting throughout its history. A simple and very telling example of this is his works that tackle the vexations of representing the sky, or more particularly clouds and sea. This is a common problem, addressed throughout the history of painting, of form turning upon formlessness.

By far the most confronting and controversial work Richter has produced to date fits within this category of historical self-reflexivity. The October 18 , 1977 (I988) series is painted from police and newspaper photographs of the events surrounding the crimes, arrests, and deaths in custody of the socalled Baader-Meinhof Gang. The issues raised in the other photo-paintings that I have shown are compounded in this particular series because what is at stake for representation is amplified by its relation to controversial events in recent history - events that were presented from radically different political points of view at the time and since. In taking up these events as a suitable subject for painting, Richter opens up a variety of old wounds: first, for the German government, which the Baader-Meinhof Gang threatened so effectively and, second, for art itself in terms of questioning painting's ability to represent history at all, at having perhaps lost this contract to photography.

The photographic blur and "out-of-focus-ness" are again at the base of the poignant affect of these images. This is made particularly obvious in contrast to the comparatively traditional portrait of Ulrike Meinhof, titled Youth Portrait (1988), which is also part of the series. This painting tends to act as a 
"before" image: a young, composed, and unexceptional woman turns toward the viewer. Although somewhat lacking in definition and rendered in the same somber, gray-black monochrome as the rest of the series, this painting largely meets expectations of the genre of portraiture and communicates the sense of unassailable optimism so characteristic of studio photo portraits of the young. The other images in the series are "after" images in two senses. They come after the possibility of a happy future, after the death of the young woman in fact and are themselves the after images that remain in the wake of extreme visual (historical) phenomena. Despite possessing the greatest visual clarity of the series, Youth Portrait seems to return an impression that is furthest from the "realities" of the situation. It shows nothing of what is to come, nothing of what are to be the major constituting actions and events in the young woman's life, and certainly not the proper name, which would link her to the disturbing events of which she was a part. But if Ulrike Meinhof is not present in this image, she is no more present in the paintings that show her dead body lying in profile, the absence of Meinhof as subject paradoxically underscored by the repetition of this near-identical image.

In the space of the extended temporal engagement that painting generates with these images, who does not look for the rope mark around the neck in each of these paintings titled Dead Woman? Who does not peer into the confused interior of Hanged in an effort to make out a suspended body? This attention to photographic detail in photography proper can be ghoulish, but to render the same information in painting is to legitimate that our interest relates to the acculturation of the gaze by which we are licensed to look long and hard.

Photography is inherently suited to its role of representing history as the essential rhetorical structure of the medium parallels that of traditional historical discourse. ${ }^{10}$ The enunciative structure of both history and photography elide a subject position between the referent and its depiction. Just as for Roland Barthes "history seems to write itself," the photograph seems to make itself." Despite a well-established critical discourse existing around these issues, photography is still viewed as capable of functioning as an indexical record of a disparate range of events. The fact that photographic evidence is admissible in a court of law and that photography is used extensively by policing agencies is a simple test of this.

The genre of historical representation has been changed by photography. Perhaps the claims of photography (as well as film and video) on historical 
representation are so strong as to make painting laughably redundant in this role. Certainly the temporality of narrative structures and painterly production means that in comparison to the speed of photographic or digital registration, reproduction, and reception, painting is always too slow, "always too late." ${ }^{12}$ These paintings were made in 1988 , and Richter makes clear their "lateness," or perhaps their being too soon, by titling the series with the date of the deaths in 1977 . But in addressing events of recent history in painting, Richter reanimates debates around these issues and continues to struggle with the possibility of the modern history painting, not convinced of photography's claim to the genre.

Through blurring, smudging, and streaking the paintings, the photographic clarity and visual cohesion from which they originate is obliterated, and with it, their claim to offer up the subjects they represent is lost. Richter's obscuration marks the dirty window from which the view is taken, and this is at the same time the violent mark of rejection of the "spotless mirror" that photography has been so often compared with. These diffuse images make Richter's mediating role, as subject between the image and the object, abundantly clear. In denying himself the hiding place of assertive photographic veracity, he also reveals the photographer, associated photographic institutions, and the apparatus of history as mediating subjects.

To question photography's adequacy for the task of representation is to threaten certain epistemological certainties that rely on the possibility of representation as such. This is an issue with which I want to conclude. The effect of each of Richter's systematic photographic citations has in all cases relied on deliberately obscuring the image. While this obscurity is an effect of the idiom of photography being rendered in contemporary painting, obscured images are an easily discernible style of imagery in art history. Richter knows this history and, at a certain level, we need to know it so as to recognize that his research on the idiom of photography is about an already established topic in art history, that of obscurity. Despite their diversity, Leonardo's sfumato, the disconcerting tenebrousness of Rembrandt, and Goya's bleak "black paintings" all share a visual ambiguity that is their strength. As Turner is famously said to have responded to the complaints of some clients, "Obscurity is my forte." Obscurity is also a persistent trope in photography itself-most notably in photographic pictorialism, but also in contemporary photographic art practice such as the work of photographers like Hiroshi Sugimoto and Uta Barth. 
Rather than obscure images being less informative, or less true to perception and visual experience, such images can be seen to more adequately parallel perception and its limits and analogously refer to the limits of representation more generally, to be more truthful in their explication of what is idiomatic to all language. This obscurity can be understood through recourse to perhaps the oldest story we know of art. This story comes from Pliny and Duris:

The classical tale of the painters Zeuxis and Parrhasios tells of how Zeuxis painted some grapes that were so realistic that sparrows swooped at the canvas and pecked at them. Parrhasios asked Zeuxis to his studio where he would demonstrate a similar feat of artistic skill. Once in the studio and in front of the work, Zeuxis asked Parrhasios to draw back the curtain which hung across the canvas so that he might assess his efforts. The curtain was in fact painted. In acknowledging Parrhasios' superior skill Zeuxis said, "I took in the sparrows, but you took me in." ${ }^{13}$

The story of Zeuxis' grapes is familiar, yet the second part of this story, relating to Parrhasios' triumph, is far less often quoted, perhaps because it has been seen to merely repeat the example of the grapes. These two visual strategies are, however, very different and the nature of their difference has important and complex implications regarding painting, representation, and, for this discussion, Richter's photo-paintings. Parrhasios' trompe l'oeil demonstrates his greater cunning and skill, but most of all it points out a condition, or rather the position, of all representation. Zeuxis overlooks Parrhasios' curtain as object, instead interpreting it as lying between him and the thing represented. That the curtain is the thing that is represented rather than being a real curtain concealing the object of representation places the curtain in the position of representation -that is, Parrhasios shows the curtain as representing representation. The curtain is always between the viewer and the object, just as representation is only ever between the viewer and the object; it does not exist outside that relationship. Most images would have us forget the fact that what we see when we see an image is the curtain, or veil, or screen, or canvas of representation, its very fabric.

If this is the case, you might ask, Where is Zeuxis' curtain? Unlike Parrhasios' curtain, it is transparent and invisible, but it is there in the very stuff 
of representation, the conventions of art history, of painterly technique, of composition, and so on-all the things that we are so familiar with as to allow their transparency. After all, like hungry sparrows, we only want to see the grapes. And just as Zeuxis was taken in by Parrhasios' ruse, we are all taken in by representation. For at the most fundamental level the "success" of representation lies in its being taken for the object or idea it represents. In this way, the allegory essentially describes two different modes of representation: the first elides the picture plane, the second makes it paradoxically present.

Richter's photo-paintings can be understood as operating through both these models: first, in terms of the photographic truth effect, which parallels the realism of Zeuxis' grapes and, second, through the trompe l'oeil of photographic idiom, which recalls Parrhasios' curtain. For Richter, this second mode is clearly the most productive. Parrhasios' curtain, or veil, is the veil of representation. It is most often diaphanous, entirely transparent to the view. The transparent veil is all too ready to show what lies behind it as if there were no behind, as if there was no mediating membrane between the object of representation and its inscription on a suitably receptive surface. Richter's photo-paintings refuse the transparency of this veil, marking out the process of representation through referring to the trace of its conventions, be they photographic or painterly. Parrhasios' mechanism for foregrounding representation is the trompe l'oeil curtain; Richter's is obscurity, the blurred, diffuse, or tenebrous. The compelling quality of his paintings resides as much in what they do not show as in what they do show.

Certainly Richter's blurred and out-of-focus images seem to place a visible barrier between the viewer and the referent, it is a barrier "behind which objects and people disappear." ${ }^{14}$ This barrier, the surface of the canvas, is made highly visible in Richter's photo-paintings. He applies paint, spoils his carefully laid down images, scrapes paint off, and reveals the very weave and weft of the fabric. In the process of marking out the surface of the representational illusion, he also of course demonstrates the means of his representational ruse. It is as if Parrhasios had said to Zeuxis, "Look, I have painted a curtain." So too, with Richter, it is as if he insists on the materiality of the representational surface or, if you like, the stage of the theatre of representation through drawing attention to its physicality. By working, reworking, and exposing. Through these painterly citations of the photographic, he paradoxically emphasizes painting as process, canvas as surface. 
Of course in doing so, he clearly engages in another type of theatricality, but this serves to demonstrate that despite the inadequacy of our means we continue to persist.

My discussion has then considered the promises of three figures from across art history, Parrhasios, Cézanne, and Richter. Parrhasios' promise is a promise fulfilled. He not only takes in Zeuxis but he provides us with a figure with which to consider the theatre of representation across art history. Cézanne's promise, entailed in the statement "I owe you the truth in painting and will tell it to you," was certainly painted by Cézanne, but who can say if it was told? Although Richter gestures toward such a judgment when he claims, "I consider many amateur photographs better than the best Cézanne," the promise Richter himself makes is to paint a photograph and by so doing to tell the truth. ${ }^{15}$ Yet the nature of this telling and the form of this truth amount, of course, from Parrhasios onward, in the most beautiful lies.

What is idiomatic to photography is the truth effect, but this is paradoxically communicated through blur and lack of focus as much as through clarity. In transferring the signs of this truth effect from photography into painting, Richter cites photographic idiom. Within painting this citation of photographic idiom is able to represent truth, as per photography, but also more generally as the truth of the limits of representation in both media, all media. The truth of representation is, like Parhassios' curtain, that all representation takes place as a staged, mediated event where curtain, paper, canvas are the transport for the idea. This greater, all encompassing truth is only made evident through the rendering of photographic idiom in painting. It is only possible through the effect of painting's idiom, it is not evidentin fact it is hidden - in photography as medium. Painting needs the supplement of the photographic idiom in order to set the contours of both media atremble and to make these "truths" visible. ${ }^{16}$

\section{Notes}

I Jacques Derrida, The Truth in Painting, trans. Geoff Bennington and lan McLeod (Chicago: University of Chicago Press, 1987).

2 Cézanne's letter to Emile Bernard, October 23, 1905; cited in Derrida, Truth in Painting, 2.

3 Ibid., 7 .

4 Gerhard Richter, "Interview with Rolf Schön, 1972," in The Daily Practice of Painting: Writings 1962-1993, ed. Hans-Ulrich Obrist, trans. D. Britt (London: Thames and Hudson and Anthony d'Offay Gallery, 1995), 73. 
5 As discussed by Samuel Weber in the seminar series "Medium Cool: Recent Developments in Aesthetics, Cultural Studies, and Critical Theory," Queensland University of Technology, Brisbane, Australia, 1998.

6 Richter, cited in Gertrud Koch, "The Richter-Scale of Blur," October 62 (1992): 133-42; quotation from 133 .

7 Ibid.

8 Richter, "Notes 1986," in The Daily Practice of Painting, 131.

9 Richter, "Interview with Benjamin Buchloh, 1986," in The Daily Practice of Painting, 158.

Io Roland Barthes, "Historical Discourse," in Structuralism: A Reader, ed. Michael Lane (London: Cape, 1970), 145-55.

II Ibid., 148.

I2 Stefan Germer, "Retrospective Ahead," in Gerhard Richter, ed. Sean Rainbird and Judith Severne (London: Tate Gallery, 1991), 22-3r; quotation from 23.

13 Ernst Kris and Otto Kurz, Legend, Myth, and Magic in the Image of the Artist: A Historical Experiment (New Haven: Yale University Press, 1979), 62.

14 Koch, "Richter-Scale of Blur," 142.

I5 Richter, "Text for Exhibition Catalogue, Galerie h, Hannover, 1966, Jointly Written with Sigmar Polke," in The Daily Practice of Painting, 55.

16 As discussed by Samuel Weber in the seminar series "Medium Cool." 